\title{
Missing persons: the processes and challenges of police investigation.
}

\author{
FYFE, N.R., STEVENSON, O. and WOOLNOUGH, P.
}

This is an Accepted Manuscript version of the following article, accepted for publication in Policing and Society. FYFE, N.R., STEVENSON, O. and WOOLNOUGH, P. 2015. Missing persons: the processes and challenges of police investigation. Policing and society, 25(4), pages 409-425. Available from:

https://doi.org/10.1080/10439463.2014.881812. It is deposited under the terms of the Creative Commons Attribution-NonCommercial License (http://creativecommons.org/licenses/by-nc/4.0/), which permits noncommercial re-use, distribution, and reproduction in any medium, provided the original work is properly cited. 
Missing Persons: the processes and challenges of police investigation

\author{
Nicholas R. Fyfe* \\ (n.r.fyfe@dundee.ac.uk) \\ University of Dundee \\ \& \\ Scottish Institute for Policing Research \\ School of the Environment, University of Dundee, Dundee, DD1 4HN
}

\author{
Olivia Stevenson \\ (olivia.stevenson@glasgow.ac.uk) \\ University of Glasgow \\ Geographical \& Earth Sciences, East Quadrangle, Main Building \\ University of Glasgow, Glasgow G12 8QQ
}

\author{
Penny Woolnough \\ (penny.woolnough@scotland.pnn.police.uk) \\ Police Scotland \\ Scottish Institute for Policing Research \& University of Dundee \\ Police Scotland, Woodhill House, Westburn Road Aberdeen, AB16 5AB
}

August 2013

*Corresponding author

Paper submitted to Policing and Society: an international journal of research 


\title{
Missing Persons: the processes and challenges of police investigation
}

\begin{abstract}
Responding to reports of missing persons represents one of the biggest demands on the resources of police organisations. In the UK, for example, it is estimated that over 300,000 missing persons incidents are recorded by the police each year which means that a person in the UK is recorded missing by the police approximately every two minutes. However, there is a complex web of behaviours that surround the phenomenon of missing persons which can make it difficult to establish whether someone's disappearance is 'intentional' or 'unintentional' or whether they might be at risk of harm from themselves or others. Drawing on a set of missing person case reconstructions and interviews with the officers involved with these cases, this paper provides insights into the different stages of the investigative process and some of the key influences which shape the trajectory of a missing person's investigation. In particular it highlights the complex interplay between actions which are 'ordered and conditioned' by a procedural discourse around how missing persons investigations should be conducted, and the narratives that officers construct about how they approach investigations which are often shaped by a mix of police craft , 'science' and 'reputational' issues.
\end{abstract}

Key words: missing persons investigation policing 


\section{Missing Persons: the processes and challenges of police investigation}

\section{Introduction: the challenge of missing persons}

Responding to reports of missing persons represents one of the biggest demands on the resources of police organisations. In the UK it is estimated that over 300,000 missing person's incidents are recorded by the police each year which equates to over 200,000 missing individuals as some individuals go missing on more than one occasion (NPIA, 2011). This means that a person in the UK is recorded missing by the police approximately every two minutes and a typical police force can expect to respond to, at the very least, one new missing person report every day (Newiss, 1999, p.3). About two thirds of those reported missing are young (i.e. under 18) with the most frequently reported missing age group being 15-17-year-olds (NPIA, 2011). Up to 80\% of all those reported missing will return within 24 hours, often without direct police intervention. Nevertheless there are still over 2000 missing people who remain absent a year after going missing and on average 20 people a week are found dead after being reported missing (NPIA, 2011; Tarling and Burrows, 2004).

It is not just the quantity of missing person reports that makes significant demands on police resources. There are also a range of more qualitative dimensions to the phenomena of missing persons which present the police with important challenges in terms of their investigative response. As several researchers have highlighted, there is an 'exceedingly complex web of behaviours and responses that surround the phenomenon of missing persons':

'While it is not a crime to go missing, there may be factors relating to the criminal justice system, either underpinning the motives of the missing person, or relating to the outcome of the missing person investigation. On the other hand, the explanation may be totally removed from any criminal dimension and could include social problems associated with mental health issues, alcohol use, child psychological abuse, child neglect or parental rejection of a child. It could be combination of both criminal activities and social problems, for instance domestic violence, child sexual abuse, child physical abuse or illicit drug use. ... The incident may relate to child abduction by an estranged parent or stranger. It could involve an older person with Alzheimer's disease or dementia. It may be a homicide or a suicide or be the result of an accident ... The list is seemingly endless.'(James et al 2008: 2)

As these observations highlight, the police face a range of dilemmas with every report they receive of a missing person. For example, they must rapidly establish whether this is an 'intentional' absence (i.e. someone has decided to go missing, perhaps to have some time away from other pressures) or an 'unintentional' absence (i.e. someone is lost, perhaps as a result of suffering from a mental illness such as dementia, or there has been a degree coercion, such as an abduction). Locating where a missing individual is on this 'missing continuum' (Biehal et al (2003)) is therefore a key challenge because it will inform what is an appropriate police response. Indeed, in determining that response the police need, on the one hand, to respect the right of an individual to go missing, particularly if there is no evidence that a crime has been committed, but, on the other hand, they have a duty to establish the well-being of a missing person, they must treat relatives and friends who have reported an individual missing with compassion, and there is always the possibility that the 
missing person may have been the victim of a serious crime and thus there is a need to preserve and gather appropriate evidence (Bayliss and Quinton, 2013). Missing persons investigations therefore share much of the 'moral ambiguity' of other aspects of police work with officers expected to secure a positive outcome (finding the missing person alive) in 'often confused, difficult and emotionally charged circumstances' (Innes, 2002b, p.73).

Against this background, this paper attempts to understand the nature of the investigative police response to reports of missing persons. Building on the work of Newiss (1999), it draws on a set of case reconstructions and interviews with police officers to provide insights into the different stages of the investigative process and some of the key influences which shape the trajectory of an investigation. In particular it highlights the complex interplay between a procedural discourse concerned with 'good practice' in the ways missing persons investigations should be conducted, and the narratives that officers construct about how they approach these investigations which are typically based around a blend of procedural, craft , 'science' and 'reputational' issues. In exploring these matters the paper aims to contribute to both the evidence-base around missing persons (a field where research is still in its infancy but see Payne, 1995 and Biehal et al, 2003) and to the literature on the processes and procedures of police investigation.

\section{The research context}

This study of the police response to reports of missing persons formed part of a wider research project which has also examined the experiences of missing adults (via interviews with individuals reported missing) and the experiences of families (see Parr et al, forthcoming; Parr and Stevenson, 2013). The research with the police has been carried out with two UK forces: Grampian Police in the north east of Scotland and which is now part of the new national Police Service of Scotland (PSOS), and the Metropolitan Police Service which covers London. The work with the police involved a detailed reconstruction of missing persons investigations using case files and interviews with the officers involved in these cases. A total of 12 cases were reconstructed drawn from the two police forces with cases selected on the basis that they exemplify different types of investigation. Some cases were graded 'low risk' and others 'high risk' and in some there was a change in risk assessment as the investigation progressed; some cases were located within a single police force while others involved cross police force collaboration; and some cases were short term (the person was missing for a few hours) while others were longer term, running over several months and in one case the investigation is still open as the person has yet to be found. Key officers $(n=21)$ involved with the reconstructed cases were interviewed, including Police Constables who provided the initial response to Senior Investigating Officers and Police Search Advisors (POLSAs). All the cases relate to missing persons investigations which took place between 2010 and 2011. In order to protect the anonymity of the individuals involved in the cases, all names and locations have been changed. As the following analysis illustrate, this work has allowed us to understand in-depth how police resources are deployed in response to a report of a missing person, decision-making 
processes within police organisations, and focus on what spatial assumptions are made and acted upon during missing events. However, in order to give a flavour of how the police respond to a report of missing person, the next section provides three case reconstructions relating to investigations which ranged from a few hours to several months. The following sections then deconstruct the process of the police response to these and other cases included in the study.

\section{Missing persons investigations: three case reconstructions}

Within the UK a missing person is defined within police policy as 'Anyone whose whereabouts is unknown whatever the circumstances of disappearance. They will be considered missing until located and their wellbeing or otherwise established' (ACPO 2005: 8). Such a seemingly simple and straightforward definition obscures the complexity of situations in which someone might be reported missing and the challenge of providing an effective investigative response. In order to provide an insight into that complexity this section provide three case reconstructions, illustrating the different contexts in which people are reporting missing and the nature of police activity in short (a matter of hours), medium (several days) and long term (months) missing person investigations. Each case also illustrates the processes of police-decision making as the inquiries progress and the ways in which information gathering and physical searching are conducted.

The search for Rachel: missing for 15 hours

Rachel lives in a small town with her 17 year old daughter. One Sunday morning Rachel tells her daughter that she is planning to go for a cycle ride with her niece and that afternoon the daughter hears the front door close and realises that her mother has left the house which she find strange given that normally her mother would state where she was going and when she would be back. When her mother doesn't return home for tea at 1700 , her daughter phones her mobile but gets no reply. At 2030 the daughter becomes concerned and enters the mother's bedroom where she finds a notebook containing several suicide notes addressed to family members. She contacts her Aunt (Rachel's sister) who phones the police. Two uniformed officers arrive about one hour after the initial report of Rachel's disappearance and initial search of her house is carried out and the Aunt is asked about areas that Rachel might frequent. The case is classified as high risk because this is seen as out of character and a second search of the property is carried out but this time supervised by a Police Search Advisor (POLSA). As a high risk case, contact is also made with Rachel's mobile phone provider but this yields no information because the phone was not on the network. A uniformed officer also interviews three friends of Rachel with whom, she had been drinking the previous evening while a Sergeant contacts all the local taxi firms and a decision is taken to contact local bus companies and to involve the police dog handler in the search. The following day a further set of checks are made. The Force Control Room makes contact with local hospitals and Rachel's GP is also contacted and an appointment made to 
meet with her doctor. An officer also visit's Rachel's place of work where she has failed to turn up while arrangements are also made to obtain DNA and fingerprint samples for Rachel in case these might be required later for identification purposes. At 11 am on the Monday morning, however, Rachel is spotted by an ambulance crew who knew her and they picked her up and took her to a local hospital to which two police constables are then sent to complete a 'cancellation' interview with her. This revealed that it had been her intention to commit suicide because of financial problems and a breakdown in family relationships.

The search for Caitlin: missing for seven days

Caitlin is reported missing to the police at $16-20$ by a housing officer who is concerned about her after council workers had reported that they had had to gain entry to her flat to carry out repair work and discovered it in a poor state with rubbish everywhere. At 18-15 police go to Caitlin's flat and search it and adjacent outbuildings as well as carrying out door-todoor enquiries of the immediate block Caitlin lives in. This yields name of her ex-boyfriend and at 19-30 police visit him and one of Caitlin's work colleagues. The same evening the police check local hospitals, speak with her mother (from whom she is estranged), call Caitlin's mobile and make checks on police databases. The following day the police meet the housing officer who reported Caitlin missing, her GP to ascertain more about her mental health, and a former workplace colleague. They also place Caitlin on the PNC and contact public transport companies given she doesn't have access to a private car. The Force Intelligence Unit also provides an analysis of Caitlin's banking details and officers conduct a further search of her flat. That afternoon a press release and picture of Caitlin are issued. An officer also visits a local supermarket to view CCTV footage following discovery of a till receipt at Caitlin's flat and further interviews are conducted with family and friends of Caitlin throughout the afternoon and into the evening, some of which reveal something of her mental state and that she had previously attempted to commit suicide. Caitlin's mother calls at 21-30 to get an update on progress but also provides views on why Caitlin might have gone missing. At 2300 the police also arrange for Caitlin's cat to be taken to an animal charity.

On Day 3, further interviews are carried out by the police with friends and work colleagues of Caitlin to gather more background regarding her disappearance and following a POLSA review later that day she is now graded as high risk with POLSA identifying a range of factors that are now causing grave concern about her well-being, including her previous suicide attempts, that she suffers from depression, and that friends have described her as depressed and tearful. However, the POLSA still recommends a twin track approach given that while she may have committed suicide (and the most likely methods based on previous cases would be drowning or hanging) she may also just be seeking some time out. The police also organise further media appeals and make contact with Skywatch (a volunteer 
group of micro light pilots) to check the surrounding countryside. Consideration is also given to the deployment of an underwater search unit.

On Day 4 Skywatch and a police dog unit are deployed to search the local area. Following a review of the case by the duty Inspector consideration is now given to handing the case over to CID but in the interim further work is carried out by uniformed officers including door-todoor inquiries, re-interviewing the boyfriend, and an examination of Caitlin's lap top. On Day 5 further checks are carried out in relation to movement on her bank account, whether her passport is valid, and whether she has had any contact with the DSS. The POLSA also offers further advice suggesting the search strategy should now focus on possible suicide locations with the most likely scenarios being an overdose or hanging. On Day 6 further attempts are made to examine Caitlin's mobile phone and the home of one of her brother's is searched. On Day 7 a member of the public contacted the police to say that he saw a person sleeping in a tent in a wooded area while out walking his dog and when officers arrived at the scene found Caitlin in the tent, located about one mile from where she was reported missing. She was then taken to a local police station where she was assessed by a doctor who said she was not clinically depressed or suicidal.

The search for Adam: missing for 3 months

Two days after attending a New Year's Eve party, Adam, a 19 year old, is reported missing by his mother because he hasn't been seen since the party. At 15-45, an hour and a half of receiving the report, two uniformed officers arrive at the mother's house (where Adam also lives) and speak with her about his disappearance and search the house. They obtain a recent photograph, his mobile phone (which he had left to charge before going to the party) and his bank details. By early evening his details have been entered on the Police National Computer, his sisters have been interviewed and their homes searcher and CCTV requested for the area in which he was last seen. Police and hospital databases are also checked. On Day 2, a press release is issued and a reconstruction of the route from the last known sighting to his home. A POLSA is brought in to the inquiry and advises Adam's bedroom should be searched by trained search officers for any information on why he might go missing and an underwater unit be deployed to search the river which Adam might have walked beside as a short cut from the location of the party to his home. On Day 3 local searches continue via door-to-door inquires, checks of wheelie bins and outbuildings along the route he might have taken, and a search of the house where the party was held for signs of assault. Ownership of the case also passes to detective and a Senior Investigating Officer (SIO) is appointed as well as a Family Liaison Officer (FLO). Over the following 8 days the physical search continues as does the search for intelligence as to why he might have gone missing and for clues as to his whereabouts. Several reported sightings of Adam are received all of which are followed up and several media appeals are made. On Day 12, Adam's mother is told the search is to be scaled down. Over the following weeks the family continue with their own efforts to trace Adam, including using social media and a 
clairvoyant. Two months after his disappearance a training shoe is found in the river that had previously been searched an attempt is made using DNA to establish whether it belonged to Adam. Almost three months after his disappearance, the body of a young man is discovered by a dog walker near the mouth of the river and the clothing matched that worn by Adam when he went missing and body also only had a single training shoe. The body is confirmed as that of Adam and the Family Liaison Officer and Senior Investigating Officer inform his mother.

\section{Unpacking the process of investigation}

These three case reconstructions begin to give a sense both of the diversity of situations in which people go missing ('intentional' in the cases of Rachel and Caitlin, 'unintentional' in the case of Adam) but also of the deployment of a similar 'investigative methodology' by the police. Echoing the work of Innes (2002a) on homicide investigation, the police responses to reports of missing persons exhibit a 'process structure' with the investigation 'oriented around an ordered sequence of actions... [which] can be seen to share similar dynamics and trajectories in terms of how they are enacted (2002a, p.672). Indeed, it is important to recognise the similarity of investigative approach deployed with a missing person and with a 'wanted person' in a homicide. As one officer observed, 'On the murder squad if you want to find out why somebody dies, you've got to find out how they lived. You've got to know everything about them, their lifestyle, which hopefully will help you identify a motive for why they've died. In a similar way if you know their [a missing person's] lifestyle it will help you find them and give you a better chance to find them'. (Detective officer). Moreover, just as homicide investigators are able to draw on the Association of Chief Police Officers (ACPO) 'murder manual' to provide professional guidance on an investigation, so too those working on missing person inquiries have access to the ACPO (2010) Guidance on the Management, Recording and Investigation of Missing Persons. This covers areas such as initial reporting, the assessment of risk, processes of investigation and working with other agencies. Nevertheless, as several policing scholars have highlighted, one of the main challenges for those studying police work' on the ground' is finding a way of capturing and representing its complexities when policing is 'enmeshed in a web of situational and structural contingencies' (Innes, 2008, p. 15). In this section we attempt to unpack some of these complexities and reveal something of the 'process structure' of a missing persons investigation. Following Newiss (1999) and the ACPO (2010) guidance this can be broken down into three key stages of investigative activity: the initial response, further investigation and searching, and what happens when the person is found.

The initial response 
As the three reconstructions illustrate, reports of missing persons will typically first come to the attention of the police as a result of a phone call. The first person to deal with a report is therefore normally a civilian 'call handler' at a force contact centre or control room. In many cases, however, the reports of a missing person are ambiguous and confusing. For example, it is quite common for the caller to say that they are 'concerned' about somebody, perhaps because they are late returning from an event or have not turned up for work, rather than to formally report them missing. The initial police response therefore is focused on establishing a 'definition of the situation' and in particular assessing whether the person may be at risk and whether there is something suspicious about their disappearance. Following an established protocol comprising a series of questions, the call handler will attempt to gather sufficient information so that the senior duty police officer within the control room can determine an appropriate level of police response. Typically, the questions posed by a call handler are focused on establishing:

- What is the specific concern?

- Is this out of character?

- Does the person have specific medical needs?

- Is the person likely to be subject to crime?

- Is the person the victim of abuse or at risk of sexual exploitation?

- Is the person likely to attempt suicide?

- Do they pose a danger to other people?

The responses to these questions (some or all of which may also be asked again by a uniformed patrol officer dispatched to speak with the caller face-to-face) provide the intelligence for an initial risk assessment of the case which will be made by a Sergeant or Inspector. If the case involves someone who has gone missing before, is not deemed to be vulnerable based on their age or medical history and has access to money the case would normally be graded 'low risk'. Where the case involves one of more of the following elements they are likely to be graded high risk: someone for whom going missing is viewed as out of character; they are likely to come to harm or who might harm the public or themselves,; is vulnerable because of their medical history, has no money, or is not adequately dressed for the prevailing weather conditions. This risk assessment effectively provides a way of assessing the 'situational qualities' of the missing incident all of which will then inform the pace, scale and direction of the subsequent investigation (see too Newiss, 2004 and Newiss, 2005). As further information is gathered on the case, the initial risk assessment will be reviewed to ensure that the police response remains proportionate to the perceived risk. In relation to the three case reconstructions, for example, both Rachel and Adam's disappearances were graded high risk from the beginning because it relatives and friends were emphasising that it was 'out of character' for them to go missing; Caitlin by contrast had gone missing before so she was not immediately classified as a high risk but as information comes in about her mental state she is re-classified as high risk on the basis she might be suicidal. As Ericson and Haggerty (1997) have noted, however, in any process of 
risk assessment 'measurement is inexact, statistical probabilities are imprecise, and indeterminism, therefore is ever present' (p.92) and this, as our introductory comments noted, is a particular challenge in the context of the moral ambiguity of missing person investigations

As the three case reconstructions also highlight the police will normally undertake a series of actions within the first few hours from when a report is received that will attempt to provide a rapid assessment of the nature of the person's disappearance. These actions may vary depending on whether the person has gone missing from their home address or from an institution, like a hospital, but typically include undertaking a physical search of the missing persons residence (in case the person is in fact hiding or has been hidden within their home or has left any immediate clues, like a suicide note) and a search for intelligence which may indicate the whereabouts of the missing person. The latter will include checking relevant police data bases and intelligence systems for evidence that the missing person may be at risk from abuse or violence, checking admissions to local hospitals, constructing a list of associates, friends and frequented places, and asking about their ownership of mobile phones and use of social media. The police will also request a recent photograph of the missing person so that these can be rapidly circulated to other officers. In an interview, one patrol officer described the questions he asked in a case involving a young male reported missing by his mother, after he disappeared from his home address after drinking and arguing with his mother:

What they've done in the past when they've gone missing, what the specific circumstances were this time, like what led up to them leaving, what they've said, what they've had to drink, medical history if they know it, any causes other than their argument, like he was going through a separation' (Patrol officer)

Another officer described the response of those who have reported someone missing as being like 'they're a waterfall just gushing information of what they think might be useful and they give you last known places that they've found him, places they like to go, places they've said they wanted to go' (Patrol officer)

However, officers are also having to make initial assessment of the validity and reliability of the information that is being provided: 'You have to assess whether its relevant and whether you think it's a factor and whether you believe ... what they're saying or not' (Patrol officer) and officers also spoke about 'gut feelings' in relation to anything potentially suspicious, 'a feeling that something they're saying isn't' right'. Such responses are further reinforced at a formal level within the ACPO (2010) manual which has the clear instruction 'If in doubt, think murder'. 


\section{Further investigation and searching}

The next stage of an inquiry is an attempt to expand the police's knowledge of the disappearance and extend the spatial boundaries of searching beyond the missing person's home address. In some respects, this is the equivalent to the 'information burst' stage described by Innes(2002a) in homicide investigations as the police begin the process of accumulating more detailed knowledge about the person and executing a more intensive and extensive search strategy. Typically if the person is not found with a few hours and they are graded as high risk, a 'division of investigative labour' rapidly begins to emerge shaped by the administrative-management structure of police organisations, resulting in greater task specialization, as the initial inquiry passes from uniformed officers to detectives and the expertise of POLSAs, Family Liaison Officers, and external search organisations is called upon. In terms of gathering more information, officers will typically re-interview key informants they spoke to during the initial response as well as extend the people spoken to include other significant people connected to the missing persons, such as members of their extended family, close friends, former partners, as well as their doctor and work colleagues. The focus of these interviews is often around establishing possible motives for the person's disappearance, where they might have gone to, how they might be moving around as well as their degree of vulnerability in terms of medical conditions and what type of clothing they have. In addition, a process of 'data mining' is undertaken of any sources that might reveal the movement of the individual. CCTV evidence is reviewed, mobile phone and public transport companies are contacted because of their ability to track use of phones and travel cards (such as Oyster cards in London), the Department of Work and Pensions may be contacted about whether benefits are being drawn and, in high risk cases, bank information can be accessed. As one officer explained:

The key things are things that I think are most likely to find them the quickest ... I'm looking at whether they have any bank cards on them because we can check the banks to see when and where they have taken money out; and mobile phones to phone them or see if it is being used. (Detective officer)

Much of a missing person investigation is therefore 'information work', involving material from a variety of sources, such as witness statements, database entries, CCTV video surveillance tapes, and forensic materials such as DNA and finger prints in case a body is found. The focus is on trying to establish what has happened and keeping an open mind as to whether the disappearance should be interpreted as 'suspicious' (i.e. a crime may have been committed, possibly murder). This means 'information' needs to be assessed for its reliability and validity, and therefore whether it can be trusted, and taken as 'fact'. As one officer explained:

You always have that [criminality] in the back of your mind at the start of an enquiry....is there criminality involved in this person's disappearance? (Family Liaison Officer) 
A further challenge during this phase of an investigation is distinguishing between what is relevant and what is not and there are typically many non-productive lines of inquiry that are part of the overall dynamics and trajectory of this kind of investigation. As the case of Adam illustrated, for example, there were several reported sightings of him all of which turn out to be incorrect but need to be followed up.

In terms of the physical search, the initial work is largely undertaken by local patrol officers focusing on the immediate area and informed by information gleaned from interviews with family and friends about typical routes taken and places frequented by the missing person. As one patrol officer explained:

We initially checked the main roads because normally you'll find them walking along the roads and you search the places where they're easiest to be found and most likely to be found. After that you change to searching fields and back tracks and stuff like that'.

Also of importance in determining the parameters of the search is information about whether the person is on foot or has money to pay for public transport:

Generally you figure out the timescale, what mode of transport they have. Say its three hours he's been missing and he's on foot, he could have only travelled so far. Then you think, if he's got money on him then he could hop on public transport, get on the transport network, you figure out how far they're going to travel and where they're likely to travel to. That will give you a general area of search." (Patrol Officer)

Officers also need to consider the possibility that the missing person may return to their house and not tell the police:

Just search all the rooms, attic, just because they may have gone out the house and then come back in, snuck back in and hid in the house. I have had that happen before, it's always a bit of egg on your face if you go out searching the whole countryside and come back and there they are sitting (Patrol officer)

If the case is graded as high risk, however, a decision to request the expertise of a Police Search Advisor (POLSA) will also be taken, often within a few hours of the initial response. POLSAs are officers who have received intensive, specialist training in search strategies and were first introduced in the 1980s in response to terrorist threats where their role focused on searching for bombs and other devices that might pose a threat to important public figures such as politicians or the royal family. Over time their role has extended first into criminal investigations and, in particular, the search for drugs and weapons and, more recently, into missing persons inquiries. With regard the latter, the main role of the POLSA is to construct a search strategy and then execute and coordinate it using a range of police resources (such as local uniformed officers to carry out house-to-house inquiries, a police helicopter, an underwater unit, and dogs) as well as external organisations, such as mountain rescue teams and the coastguard. Central to the development of a search 
strategy is the process of constructing scenarios based on what has been gleaned from the case-specific interviews with family and friends but often also informed by more generic information in the form of spatial profiles of missing persons developed by Grampian Police (Gibb \& Woolnough 2007; see too Gibb and Woolnough, 2005). These spatial behaviour profiles work to locate types of missing people in likely geographic scenarios, based on police data about the typical distance travelled in time, for gender, age, risk and other factors (like potential suicide risk, or particular diagnosis like schizophrenia or access to a car; see also Shalev et al 2009). This data is now routinely drawn on by POLSAs. As one officer remarked, 'When I'm on call it's tucked under my pillow because it's quite often the first, when somebody phones me in the middle of the night saying, We've got a missing 82 year old, suicidal female', (POLSA). Using this and other data, the POLSA will also attempt is to delimit the maximum spatial extent of the search which one officer referred to as the end of the world'. In the search for Adam, for example, the POLSA very quickly concluded that 'end of the world was defined in terms of the river given previous statistics will tell you he's in the water' (POLSA).

In protracted investigations, a Family Liaison Officer (FLO) might also be used. Their role includes keeping the family informed of the police search, providing advice about contact with the media and crucially obtaining detailed information about the missing person. As one FLO explained: 'As a FLO I need to know about their family life, I need to know about their workplace and the finances and all their banking ... start digging a bit deeper rather than accepting their answers straight away' (Family Liaison Officer). The family may also be actively involved in their own search and a FLO will often provide advice and support around such activity, such as how to use social media. In addition officers mentioned that in long term missing cases some families may turn to psychics for help in locating their loved one. If a psychic says that the body will found in a particular location, the police are often under pressure to search that area even if they are not convinced the person will be there. As a POLSA observed: 'The family have brought it in and you can't ignore what the family's feelings are. As an investigating officer you can't discount it'

As the case reconstructions also illustrate, issues of media involvement often emerge early on in an investigation. As in homicide inquiries, the media was viewed as an investigative resource (Innes, 2002, p.676) which allows contact with a large population who might be able to supply important information. As one POLSA observed 'for me the single most important part of a missing person enquiry is the media appeal because there is no point in four sets of eyes looking for somebody if you can have 400 sets of eyes looking for her'. Media involvement typically involves certain 'rituals of display' such as the family press appeal, and a reconstruction of the last known movements of the person. While this might be helpful it can also increase the volume of misinformation (for example, reported sightings) as well as increasing the pressure on the police to resolve the case. 
There are also important police organisational requirements if a missing person has not returned or been found within 72 hours of the initial report to the police. At this point in an investigation, the details of the missing person must be forwarded to the national police Missing Persons Bureau where the information will be placed on their database which will allow greater coordination of the search at a national and international level if that is required. In particular it provides a way of 'matching' reported missing persons with unidentified bodies that are found at a later date.

\section{What happens when the missing person is found}

In the majority of reported missing person cases, the individual is either found alive ( by a relative, member of the public or the police) or returns in their own time. The police will then normally conduct a short interview with the returned missing person in the form of a 'safe and well check'. This interview partly provides an opportunity to find out where someone has been and why, information that then might be of value if the person goes missing again. As one officer explained, 'We need to be involved in help bringing them back and identify where they've been so that when we get another call .. then at least you know where to start looking for them' (Detective officer). In some circumstances, however, the 'safe and well check' may not yield much information, for example if the person is suffering from dementia and can't recall where they have been.

The interview might also provide an opportunity to establish what happened to the person while they were away and in particular if they had come to any harm. Officers might also make people aware of other organisations that would be able to provide support and in some cases might make referrals to those organisations. They may also explain to the person that next time they decide to go missing, they should contact the police even if they don't want to be found simply to say that they are fine and the message can then be passed on. Officers involved in these 'safe and well checks' emphasised that they wanted the person to see this has a positive experience:

It was just greet him with a smile, talk to him as a human instead of someone you've been hunting down. At the end of the day, he's not done anything wrong. We just want to find out if he's OK and what's caused him to do this' (Patrol officer). Another officer emphasized the importance of making it a pleasant experience: 'It just provides a better service, they have a better opinion of the police and maybe they won't be so averse to being found if they know it's not a horrible drawn out process once they are found'.

As in the case of Adam, some missing people are found by police, the public or other agencies only after they have died. This is relatively rare with studies suggesting that only between $0.6 \%$ and $1 \%$ of all cases reported to the police end in a missing person being 
found dead (Tarling and Burrows, 2004, Newiss, 2006). In some cases, this is because they have been out of touch for a long time and have died of natural causes before contact was re-established. In other cases, this is because the missing person has been a victim of homicide, or has committed suicide, and may have been reported missing after their death, but before their body was discovered. Where the missing person is found dead, it is the responsibility of the police to inform the family which may fall to the FLO if they have been appointed to the case. Although needing sensitive handling, few officers felt emotionally involved in such situations:

It sounds really callous, but you think 'oh well' because I don't know him, I've had no involvement with him personally other than speaking with his carers... It's my job. If I get too emotional about that kind of thing I can't do my job (Detective Officer)

I feel sorry for the families but I don't mourn their death. It's a bit cold but I think you've got to otherwise you wouldn't be doing this job (Family Liaison Officer).

\section{Key influences on the investigative process}

The processes of investigation described above are shaped by a range of influences. These include the various pieces of guidance in the form of policy and strategy documents issued by ACPO and the Home Office in order to professionalize missing person investigations (see ACPO, 2005, 2006, 2010, 2013; Hedges, 2002). While officers draw on these

'organisational' or 'procedural' discourses to inform their approach these are also mediated by important contextual issues relating to the processes of narrative construction, the craft and science of searching, and concerns about reputational risk which also shape the investigative process.

\section{Scenario-based searching and narrative construction}

A key influence on all missing persons investigation is the process of narrative construction. Officers draw on the ACPO guidance (2010) which advises the police to use 'scenario based searching' for missing people and this requires considering the reasons behind a disappearance, the motivation and ability of the missing person, and other factors that may hinder or assist a discovery when developing a search strategy. As officers explained,

I build a pen picture of that person with every possible piece of information that you have, which will form in relation to 'how far they could get physically', how far they would get mentally? what are their capabilities for travelling on public transport? (POLSA)

You try and think about them, if I was that person where would I go, what would I do? You can only do that if you've got enough information about them. ... You do need a lot of information to try and figure out what's going on in their head (Detective Officer) 
Again, much like in a criminal investigation, 'the narrative the police construct ties people, places, objects and phenomena together in a plausible chronology that provides details as to what happened and a degree of explanation as to why' (Innes, 2002, p.682). This process is not straightforward as the example of Caitlin indicates. In this case, the POLSA and other officers involved in the inquiry initially favoured a narrative focused on suicidal intentions based on information that Caitlin appears to live in squalid conditions, cries easily, anti-social and friendless with no hobbies and interests. One of the first officers to respond to the enquiry, explained in an interview that 'going by the state of the property, it was clear she might not be of stable mind ...it just builds a bigger picture that a bit more of a concern. Speaking to neighbours, speaking to the ex-boyfriend, by the end of that shift, I was thinking this person would be found dead in the next few days'. In fact she is found and located 'alive and well' and is assessed as not suicidal, nor depressed by a police doctor. She notes to the recording officer conducting the 'safe and well check' that when she left she did not know where she was going, but went to familiar places, although none of the witnesses involved in constructing Caitlin as a suicide risk knew those places.

In Adam's case, the initial scenarios were outlined by the senior investigating officer: 'There were a few possibilities of what could have happened to him; it could be a deliberate disappearance which didn't seem particularly likely, he could have suffered some sort of accident like falling into the river or such like, probably the most likely, or he could have been the victim of some sort of criminality.

The initial narrative developed by officers was that this was an accident given that the 'intelligence picture' rapidly put together around Adam in the first few hours of the inquiry was that this was a young man, not suicidal, with no links to crime, not on medication, with no reason to go missing and that on one of the routes he could have taken there is a pathway alongside a river and there were slip marks on the riverbank. So the initial assumption was that he slipped into the river. When his body is not found, however, and other information comes in to the investigation team, other scenarios need to be considered and alternative narratives begin to emerge. For example, a report comes in that he has been seen arguing with a girl in the street so the search shifts to another location within the town and attempts are made to identify the woman. Another possibility also emerges when information is received that a known criminal who had been involved in a case of abduction in the past was also in the town the night Adam disappeared. Further investigation reveals that this individual had not been in contact with Adam.

Clearly the narrative developed by detectives in a case is of key importance because it is not neutral: it constrains and directs the search for missing people and is oriented by a sense of who the 'audience' is and their expectations and interests. For example, senior officers constitute an important audience for the narrative as they will review the progress of an inquiry and will want to be reassured that formal guidance and procedures are being followed. The family and friends of a missing person are also an important audience and will 
typically want to see the police doing 'something' in terms of searching. The public, too, are an important audience in terms of the potential reputational risk to the police as an organisation if, for example, a missing person's body is found by a member of the public in an area the police have claimed to have searched or if the police failed to follow up some information provided by the public.

\section{Missing Persons Investigations as a 'craft' or 'science'}

Closely linked to the issue of scenario building in missing persons investigations is consideration of whether the process of search is viewed by officers as a 'craft' activity, those "ways of doing policing, often learned informally, "on the job", rather than through prescribed tuition' (Innes, 2008, p.,15) or a science in the sense that it is based on more formal evidence-based approach. As was highlighted many police officers make use of the spatial profiling 'toolkit' for missing persons developed by Grampian police which provides information on the most likely locations where someone might be found based on variables ranging from age and gender through to their mental health condition. Others spoke of the formula 'POA X POD = POS' (where POA is the probability of the area you are looking in, POD is the probability of detecting them, and POS is the probability of success, see Syrotuck, 1975). For many officers interviewed, the Grampian data did provide a critical investigative resource:

It's easy to get distracted and a sighting six miles away on the A2 might be strong and all the forces might go there, but I'd say ... look at the Grampian statistics, I'm not saying totally discount the sighting six miles away because it might be a genuine sighting but I wouldn't divert everything from there because that's what Grampian would say or suggest. (POLSA)

Other officers, however, were keen to emphasise that the 'science' associated with the Grampian 'toolkit' (or other similar work in the UK by Perkins, Roberts and Feeney (2003) and in the US, see Koester, 2008, and Syrotuck, 1976) was a necessary but insufficient basis for informing the process of search. Of crucial importance were 'instinct', 'gut feelings' based on experience:

'They [the Grampian data] are only statistics and a lot of the missing person element is you go by your guts really. It's what you think, what do you think this person has done and for every single missing person it's a totally individual case' (POLSA)

The problem with missing person searches is its' not a science. It's very difficult to say, this is what you must do' and I think that scenario based search is probably the closest they've got to have a structure for looking for a missing person. A lot of it before was gut feeling. ... you're never going to get an exact science.. but a gut feeling system, scenario based and that what's taught now. (POLSA) 


\section{Reputational risk}

A third key theme to emerge in interviews with officers was the high level of reputational risk associated with missing person investigations. Part of that risk related to individual officers and in particular the POLSA. As one POLSA explained, there is considerable pressure on them during an investigation: 'it becomes very draining for you ... when you've got this responsibility to keep coming up with solutions'. That pressure is particularly acute if the person is not found and the POLSA feels under pressure from a Senior Investigating Officer to ' wrap a case up [and] say I have done all I can', particularly if the financial costs of the search are high. If a search is then called off and the person is found soon after by a member of the public then those involved in the search are often anxious to establish whether this was in an area they were responsible for searching.

In addition to the individual reputational risk, is the risk at an institutional or organisational level if a police force is seen to fail to offer an appropriate level of response to a report of a missing person. To reinforce this point, several officers interviewed highlighted how some Chief Constables had lost their jobs partly as a result of perceived failures with missing person investigations. Those failures might relate to the speed of the response in high risk cases. As one officer recalled in relation to a missing person suffering from a mental illness, 'There was a delay in reporting. He'd gone missing in the morning, it was brought to our attention that day, maybe 12 or 1 o'clock and it was something like within an hour of it being brought to my attention he was dead [ the person had jumped off a car park roof]. Management were concerned if we as a borough messed up, our management were worried about their culpability'

Another element of organisational risk is related to the police search strategy and the risk that this is not executed effectively. As one officer explained:

So if we're looking for an old lady who's missing and she's found hooked up in a hedge in the back garden, the [police] force couldn't live with her being found there... that would be terrible to the reputation of the force and you'd rightly be criticised for it. If she was found 2 or 3 miles away it's reasonable to expect that you wouldn't have searched the area. So if she is found there it would be the same impact as if she was found having jumped off the Forth Bridge in Edinburgh' (POLSA).

In Adam's case, for example having not found the body in the river which was thought the most likely scenario, the decision was taken to search all front and back gardens because as the POLSA acknowledges it 'comes back to what can you live with... You couldn't live with him being found in somebody's back garden'.

\section{Conclusions}


This paper has attempted to provide a range of empirical insights into the investigative processes associated with missing persons inquiries. From the initial police response, through the physical searching of space and the search for information, to what happens when the person is found (alive or dead), it is clear that investigations follow a particular trajectory, with the 'facts' of a disappearance 'progressively and incrementally constructed through a structured process of inquiry' (Innes, 2002a, p.686; see too Innes, 2002b). Echoing the work of Innes on homicide investigations, this has, at a more conceptual level, helped reveal the 'process structure' of a missing person investigation. Police organisational actions are, as the case reconstructions illustrate, 'fluid and situated' reflecting the individual characteristics of cases and the different levels of risk associated with a disappearance, but at the same time these actions are also 'ordered and conditioned', a product of the development over time of investigative methodologies and protocols which have shaped an understanding of what 'good' practice in a missing persons inquiry involves.

Nevertheless, as the introduction to this paper highlighted, missing person investigations make a significant demand on police resources and, at a time when many police forces in the UK are having to make significant budget cuts, such pressures clearly become even more acute. Against this background, a new approach to the initial response to the report of a missing person has been piloted in the UK as part of wider attempts to increase police efficiency and reduce bureaucracy (Bayliss and Quinton, 2013). This new approach (now adopted across the UK, see ACPO, 2013) focuses on attempting to make the police response more proportionate and risk-based by no longer requiring officers to attend incidents involving people who are not where they are expected to be but are not thought to be at risk. Such people are classified as 'absent' rather than 'missing' and where this new approach has been piloted there has been over a $20 \%$ reduction in the total amount of time spent on the initial police response. Given that 'absent' is only used in low risk missing cases there has, it is claimed, been no impact on public safety and no evidence that anyone was harmed as a result of this change in the classification process.

This kind of policy innovation is important but as this paper also shows the police response to reports of missing persons will always involve a complex interplay between a policy or 'procedural' discourse of how investigations should be carried out, and the 'craft' skills of individual officers developed on the basis of experience. This in itself raises an important policy issue as to whether it is better for specialist units to take responsibility for all missing person inquiries within a police force, given they will have that 'critical mass' of investigatory experience and expertise, or whether this should simply be part of the portfolio of tasks undertaken by the 'omnicompetent' patrol or detective officer guided by a 'how to' manual. For individual officers there was a strong sense that guidance on policy and practice only take you as far and that, as in other areas of police work, it was experience that mattered most. As one officer remarked in relation to missing person investigations: 
'What you're probably looking is for a calculated structure around how we do it, but I don't think they always work. It does rely on somebody's experience. It's not just about being methodical, a series of actions and enquiries that you do; sometime it's an instinct' (Detective officer).

\section{Acknowledgements}

The research on which this paper is based was funded by ESRC as part of the project 'Geographies of missing people: processes, experiences, responses' (062-232492). We would like to thank officers from Grampian Police (now part of the Police Service of Scotland) and the Metropolitan Police Service for all their assistance in providing access to data and police personnel for this study. 


\section{References}

Association of Chief Police Officers (ACPO) 2005. Guidance on the management, recording and investigation of missing persons. [online] Available at <www.gpdg.co.uk/ pact_old/pdf/MissingPersonsInteractive.pdf.> [Accessed 22/05/2013]

Association of Chief Police Officers (ACPO) 2006). Practice Advice on Search Management and Procedures. Wyboston: National Centre for Policing Excellence.

Association of Chief Police Officers (ACPO) (2010). Guidance on the Management, Recording \& Investigation of Missing Persons. Wyboston, National Centre for Policing Excellence. [online] Available at <www.npia.police.uk/en/17187.htm>[Accessed 22/05/2013]

Association of Chief Police Officers (ACPO) (2013). Interim Guidance on the Management, Recording \& Investigation of Missing Persons 2013. Wyboston: College of Policing.

Bayliss, A. and Quinton, P. 2013. The initial police response to missing persons: an evaluation of a more risk-based approach. London: College of Policing.

Biehal N., Mitchell F and Wade J 2003. Lost from View: A Study of Missing People in the United Kingdom. Bristol: Policy Press.

Ericson, R. and Haggerty, K. (1997) Policing the Risk Society. Oxford: Clarendon Press.

Gibb G and Woolnough P 2007. Missing persons: Understanding, planning, responding - $a$ guide for police officers. Aberdeen: Grampian Police. [online] Available at $<$ http://www.sipr.ac.uk/downloads/missing persons understanding.pdf> [Accessed 22/05/2013]

Gibb G and Woolnough P 2005 (Unpublished report). The Crystal Ball is Dead: Developing a data driven risk assessment tool. Aberdeen: Grampian Police.

Hedges C . 2002. Police Officers Guide to the Investigation of Missing Persons. London, Home Office.

Innes, M. 2002a. "The process structures of police homicide investigations", The British Journal of Criminology (42/4) pp. 669-88.

Innes, M. 2002b. 'Organizational communication and the symbolic construction of police murder investigations', British Journal of Sociology, 53(1), pp,67-87. 
Innes, M. 2008. 'Towards a Science of Street Craft: The Method of Reassurance Policing', in M. Easton et al, (editors) Reflections on Reassurance Policing in the Low Countries. The Hague: Boom Legal Publishers, pp.15-28.

James M., Anderson J., and Putt J. 2008. 'Missing Persons in Australia'. Canberra: Australian Institute of Criminology Research and Public Policy Series, No. 86.

Koester R. 2008. Lost Person Behaviour: A Search and Rescue Guide on Where to Look - for Land, Air and Water. Charlottesville, Virginia: dbS Productions LLC.

National Policing Improvement Agency (NPIA) (2011). Missing persons: Data and analysis 2009/10. Bramshill: NPIA.

Newiss G. 2006. 'Understanding the risk of going missing: estimating the risk of fatal outcomes in cancelled cases', Policing: An International Journal of Police Strategies \& Management 29(2): 246-260.

Newiss G. 2005. A study of the characteristics of outstanding missing persons: implications for the development of police risk assessment, Police and Society, 15(2): 212-225.

Newiss G. 2004. 'Estimating the Risk Faced by Missing Persons: A Study of Homicide Victims as an Example of an Outcome-Based Approach', International Journal of Police Science and Management, 6 (1):27-36.

Newiss G. 1999. Missing presumed? The police response to missing persons. London: Police Research Series.

Parr et al, (forthcoming). 'Searching for missing people: families and missing experience'

Parr H and Stevenson O 2013. 'Missing People, Missing Voices: Stories of Missing Experience'. [online] Available at www.geographiesofmisisngpeople.org.uk

Payne M. 1995. 'Understanding 'going missing': Issues for social work and social services', British Journal of Social Work, 25: 333-348.

Perkins D., Roberts P and Feeney G. 2003. Missing Person Behaviour: An Aid to the Search Manager. Newport: Mountain Rescue Council England and Wales.

Shalev K., Schaefer M and Morgan A. 2009. 'Investigating missing person cases: How can we learn where they go or how far they travel?', International Journal of Police Science and Management, 11: 123-129.

Syrotuck W. G. 1975. An introduction to land search: Probabilities and calculations. Mechanicsburg, PA: Barkleigh Productions, Inc. 
Syrotuck W. G. 1976. Analysis of Lost Person Behaviour: An Aid to Search Planning. Mechanicsburg, PA: Barkleigh Productions, Inc.

Tarling R and Burrows J. 2004. 'The nature and outcome of going missing: The challenge of developing effective risk assessment procedures'. International Journal of Police Science and Management, 6: 16-26.

Word count: 9934 